\title{
Global health and environmental pollution
}

\author{
Philip J. Landrigan · Richard Fuller
}

Published online: 2 July 2015

(C) Swiss School of Public Health 2015

Environmental pollution-contamination of air, water and soil by human activity - is the largest cause of disease and death in low- and middle-income countries (LMICs). The World Health Organization (WHO) estimates that 8.9 million persons die each year of diseases caused by pollution, 8.4 million (94\%) of them in poor countries (WHO 2014a, b). By comparison, HIV/AIDS causes 1.5 million deaths per year (WHO 2014c), and malaria and tuberculosis cause fewer than 1 million deaths each (WHO 2014d).

In the world's poorest countries, the predominant forms of pollution have been indoor air pollution and contaminated drinking water (PAHO 2012). Pneumonia and diarrhea are their principal consequences. By contrast, ambient air pollution, toxic chemicals, pesticides and hazardous wastes are the predominant environmental hazards in richer countries. They are linked to noncommunicable diseases-to asthma, neurodevelopmental disorders and birth defects in children, and to heart disease, stroke, and cancer among adults (PAHO (Pan American Health Organization) 2012).

Toxic chemicals are increasingly important causes of pollution worldwide. Many thousands of new chemicals have been invented in the past 50 years. They are used in a vast array of products, are widely disseminated in the global environment and are detectable today in the bodies

This Editorial is part of the special issue "Driving the Best Science to Meet Global Health Challenges" edited on the occasion of the 9th European Congress on Tropical Medicine and International Health 2015.

P. J. Landrigan $(\bowtie) \cdot$ R. Fuller

Icahn School of Medicine at Mount Sinai, New York, USA

e-mail: phil.landrigan@mssm.edu

R. Fuller

e-mail: fuller@gahp.net of most people. Many have never been adequately tested for safety (Landrigan and Goldman 2011). Toxic chemicals are linked to a wide range of diseases.

Chemical contamination in LMICs is increasing rapidly (Laborde et al. 2015). Globalization of the chemical manufacturing industry, the recycling industry and other polluting industries is a powerful driver of this trend. These industries are relocating to poor countries where production costs are low and environmental regulations and public health infrastructure often absent. Workers and communities in LMICs are increasingly exposed to toxic chemicals, often under highly uncontrolled conditions. Examples include the Bhopal disaster in India (Mishra et al. 2009); the continuing global trade of 2 million tons per year of newly produced asbestos (Frank and Joshi 2014); the shipment into poor countries of 45 million tons per year of e-waste (Perkins et al. 2014); informal recycling of car batteries for lead scrap in third world mega-cities; and enormous releases of mercury to the environment from artisanal gold mining.

The diseases caused by pollution impose great economic costs on countries around the world-direct medical costs, opportunity costs reflecting the diminished productivity of populations damaged by pollution, and costs to health care systems (Landrigan and Fuller 2015). In the United States, the annual cost of diseases in children caused by environmental pollution is estimated to be US\$ 76.6 billion (Trasande and Liu 2011) and the cost of occupational diseases and injuries is US\$ 250 billion (Leigh 2011).

Pollution can be controlled. High-income countries have identified and controlled many of their worst problems of environmental pollution. They have developed feasible, cost-effective and replicable strategies that have reduced incidence and prevalence of the diseases caused by pollution. The most effective of these strategies, such as the 
removal of lead from gasoline and national bans on asbestos, control pollution at source. These actions provide a blueprint for pollution control in LMICs.

Pollution control yields great economic benefits. The removal of lead from gasoline has generated an estimated benefit in each annual US birth cohort since 1990 of US\$ 213 billion (range US\$ 110-US\$ 318 billion) (Grosse et al. 2002) - a cumulative benefit of more than US\$ 3 trillion. This benefit principally reflects the enormous increase in national economic productivity that followed the $2-5$ point gain in population mean IQ resulting from reduction in children's blood lead levels.

Pollution control will convey particular benefits to the health sector in LMICs (Landrigan and Fuller 2015). It will reduce incidence and prevalence of heart disease, stroke and cancer. This in turn will reduce hospital staffing needs and allow scarce resources to be directed to childhood immunization, infection control and maternal and child health.

Despite its enormous human and economic costs and the proven effectiveness of pollution control, environmental pollution has been largely overlooked in the global health and international development agendas. Environmental pollution has received less than $0.5 \%$ of global development spending. This neglect reflects a lack of sound information on the health and economic impacts of pollution; fragmentation of the pollution agenda into multiple topics-urban air, cook stoves, sanitation, chemicals, hazardous waste and toxic chemicals; and undercounting of the effects of pollution in estimations of the Global Burden of Disease.

To address the health and economic impacts of pollution, we propose formation of a high-level Global Commission on Health and Environmental Pollution. This Commission will develop and disseminate robust and scientifically credible analyses that set out the full magnitude of the effects of pollution. It will educate key decision makers about the enormous scale of the health and economic effects of pollution. It will bring pollution squarely into the international global health and development agendas.

Pollution is not an inevitable consequence of economic development. It is a problem that is solvable in our lifetime. Assisting LMICs to control pollution is a highly costeffective way to reduce the burden on limited health resources, to accelerate national development and to enhance return on investment in international development.
Widespread pollution that degrades the environment, undermines societal development, and condemns future generations to continuing poverty and endless poor health encourages social unrest, war and migration. Investment in pollution control can break this vicious cycle.

\section{References}

Frank A, Joshi TK (2014) The global spread of asbestos. Ann Global Health 80(4):257-262

Grosse SD, Matte TD, Schwartz J, Jackson RJ (2002) Economic gains resulting from the reduction in children's exposure to lead in the United States. Environ Health Perspect 110:563-569

Laborde A, Tomasina F, Bianchi F et al (2015) Children's health in latin America: the influence of environmental exposures. Environ Health Perspect 123(3):201-209

Landrigan PJ, Fuller R (2015) Environmental pollution: an enormous and invisible burden on health systems in low- and middleincome countries. World Hosp Health Serv 50(4):35-41

Landrigan PJ, Goldman LR (2011) Children's vulnerability to toxic chemicals: a challenge and opportunity to strengthen health and environmental policy. Health Aff 30(5):842-850

Leigh JP (2011) Economic burden of occupational injury and illness in the United States. Milbank Q 89:728-772

Mishra PK, Samarth RM, Pathak N, Jain SK, Banerjee S, Maudar KK (2009) Bhopal Gas Tragedy: review of clinical and experimental findings after 25 years. Int $\mathrm{J}$ Occup Med Environ Health 22(3): 193-202

PAHO (Pan American Health Organization) (2012) The environment and human security. In: Health in the Americas. Available: http:// www.paho.org/saludenlasamericas/index.php?option=com_cont

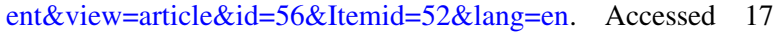
May 2015

Perkins D, Brune Drisse M-N, Nixele T, Sly PD (2014) E-waste: a global hazard. Ann Global Health 80(4):286-295

Trasande L, Liu Y (2011) Reducing the staggering costs of environmental disease in children, estimated at $\$ 76.6$ billion in 2008. Health Affairs 30:863-870

World Health Organization (WHO) (2014) 7 million deaths annually linked to air pollution. http://www.who.int/phe/health_topics/ outdoorair/databases/en/. Accessed 9 July, 2014

World Health Organization (WHO) (2014) Burden of disease from Household Air Pollution for 2012. WHO, Geneva http://www. who.int/phe/health_topics/outdoorair/databases/FINAL_HAP_ AAP_BoD_24March2014.pdf?ua=1. Accessed 9 July 2014

World Health Organization (2014) Data on the size of the HIV/AIDS epidemic: Number of deaths due to HIV/AIDS. Global Health Observatory Data Repository. WHO, Geneva. http://apps.who. $\mathrm{int} / \mathrm{gho} /$ data/node.main.623. Accessed 9 July 2014

World Health Organization (2014) Deaths: Estimated deaths, data by region. Global Health Observatory Data Repository. WHO, Geneva http://apps.who.int/gho/data/view.main.14117?lang=en. Accessed 9 July 2014 